\title{
Secretome analysis of rice suspension- cultured cells infected by Xanthomonas oryzae pv.oryza (Xoo)
}

\author{
Xian Chen ${ }^{1,2}$, Zhiping Deng ${ }^{2}$, Chulang Yư ${ }^{2}$ Chengqi Yan² and Jianping Chen ${ }^{2 *}$
}

\begin{abstract}
Background: Rice bacterial blight (BB) caused by Xanthomonas oryzae pv.oryzae (Xoo) is one of the most devastating bacterial diseases in rice-growing regions worldwide. The rice-Xoo interaction is a classical model for studying the interaction between plants and pathogens. Secreted proteins play important roles in plant-bacterial interactions, but are poorly studied in the rice-Xoo system. Rice cv. Nipponbare is highly susceptible to Xoo. Here, we used two-dimensional difference gel electrophoresis (2D-DIGE) coupled with MALDI-TOF/TOF mass spectrometry (MS), to investigate secreted proteins in Nipponbare embryo cell suspension culture infected by Xoo.

Results: A total of 32 protein spots changed significantly $(p<0.05)$ by more than 1.5 fold in gel intensity after Xoo inoculation, and were identified by MS. They represent protein products of 11 unique genes, seven from rice and four from Xoo. Of the rice proteins, six up-regulated proteins are involved in cell wall modification, the TCA cycle, glycolysis and redox, while a down-regulated protein, CHIT16, is involved in plant defense. Quantitative Real-Time PCR showed that transcript levels were not correlated with secreted protein levels. Of the Xoo proteins, three of them were possibly located in the extracellular space as shown by transient expression assays in rice protoplasts. Two of the Xoo proteins were previously reported to be likely involved in pathogenicity, and the third gene, Xoo3654, is likely a negative regulator of Xoo virulence as its overexpression reduced Xoo pathogenicity in our study.

Conclusion: Among the secreted proteins that responded to Xoo inoculation, we identified rice proteins involved in cell defense and Xoo proteins involved in pathogenicity. Our study also showed that Xoo3654 (X2) protein is likely a novel negative regulator of Xoo virulence. These results not only help us better understand the interaction between susceptible rice and Xoo, but also serve as a reference for studying the interaction between other plants and their pathogens.
\end{abstract}

Keywords: Bacterial blight, 2-D DIGE, MS, Secretome, Xoo3654

\section{Background}

Bacterial Blight (BB) caused by Xanthomonas oryzae pv.oryza (Xoo) is a vascular disease and one of the most serious diseases in rice. Xoo can invade rice xylem tissue either through wounds or stomata, causing systemic infection [1-3]. The most cost-effective way to control this

\footnotetext{
* Correspondence: jpchen2001@126.com

${ }^{2}$ State Key Laboratory Breeding Base for Zhejiang Sustainable Pest and Disease Control, MOA Key Laboratory of Biotechnology in Plant Protection, Zhejiang Provincial Key Laboratory of Plant Virology, Institute of Virology and Biotechnology, Zhejiang Academy of Agricultural Science, Hangzhou 310021, China

Full list of author information is available at the end of the article
}

disease is using resistant varieties [4]. A total of 37 resistance genes have been reported, 26 of which are dominant and the rest recessive [5]. Among these, six resistance genes have been cloned [6-11] and one of them, Xa21, is a NB-LRR protein kinase localized on the cell membrane that interacts with AvrXa21 and activates the rice immune system [9]. Due to the emergence of new physiological races of Xoo, many resistant varieties succumb to disease after a few years of cultivation $[4,12,13]$. This highlights the need to better understand the molecular basis of the complex interaction between susceptible rice and Xoo. 
Secreted proteins play crucial roles in host - pathogen interactions $[14,15]$ and recent studies of these proteins by plant proteomics have led to a new field of study, the plant secretome [16]. The aim of plant secretome studies is to describe all the proteins secreted by a cell, tissue or organism at any given time or under certain conditions, and to understand the machineries for protein transport, protein interaction and protein modification [17]. The plant secretomes of Arabidopsis thaliana [18], maize [19], tobacco [20], medicago [21] and rice [22] have been studied using the in vitro cell suspension culture system. Secretome analysis of susceptible $A$. thaliana interacting with virulent bacteria has identified some extracellular host proteins lacking the traditional signal peptide [23]. In addition, a study of the rice plasma membrane identified proteins involved in early defense response to Xoo [24]. Proteomic studies of the Xoo secretome from its in vitro culture and in infected rice leaves showed that some components of the Xoo secretome were involved in its pathogenicity [25]. However, there have been no reports of changes in the rice secretome in response to Xoo infection in this study.

Here, secreted proteins were extracted from susceptible rice embryo suspension -cultured cells at $0 \mathrm{~h}$ (mock inoculation) and $24 \mathrm{~h}$ post-inoculation with Xoo strain PXO124(P10), and labeled with fluorescent dyes. Twodimensional difference gel electrophoresis (2D-DIGE) was performed to separate proteins, Decyder 2D software was used to analyze the gel images, and MALDI- TOF/ TOF mass spectrometry (MS) was used to identify the
Xoo-responsive proteins. As a result, we discovered eight differentially expressed proteins from susceptible rice and four from Xoo.

\section{Results}

In preliminary experiments we tested three protein isolation approaches and found that the phenol-methanol method was most suitable for obtaining the secreted proteins for 2D-DIGE analysis [26, 27]. Then, we performed 2D-DIGE and MS to analyze the secreted proteins from mock and Xoo-infected rice Nipponbare suspensioncultured cells (Fig. 1). More than 500 protein spots were detected reproducibly on gels by the Decyder 2D software of which 32 changed in intensity significantly $(p<0.05)$ and by more than 1.5 fold when compared with the control. After analysis by MS, 32 proteins corresponding to 11 unique genes were matched to the NCBI database. Among those proteins, seven were from rice and four from Xoo.

Of the proteins identified from rice, six were upregulated and maybe involved in glycolysis (2,3-bisphosphoglycerate-independent phosphoglycerate mutase, spot N18, Fig. 1), redox (plastocyanin-like domain containing protein, spots N19/N21; copper/zinc superoxide dismutase, spot N28), TCA cycle (succinyl-CoA ligase beta-chain, spot N26) and cell wall structure modification (beta-galactosidase, spot N24; cellulase, spot N27), respectively. The down-regulated protein is involved in defense (CHIT16, spot N32) (Table 1). In further analysis to predict their subcellular location, SignalP software predicted that the plastocyanin-like domain containing protein,

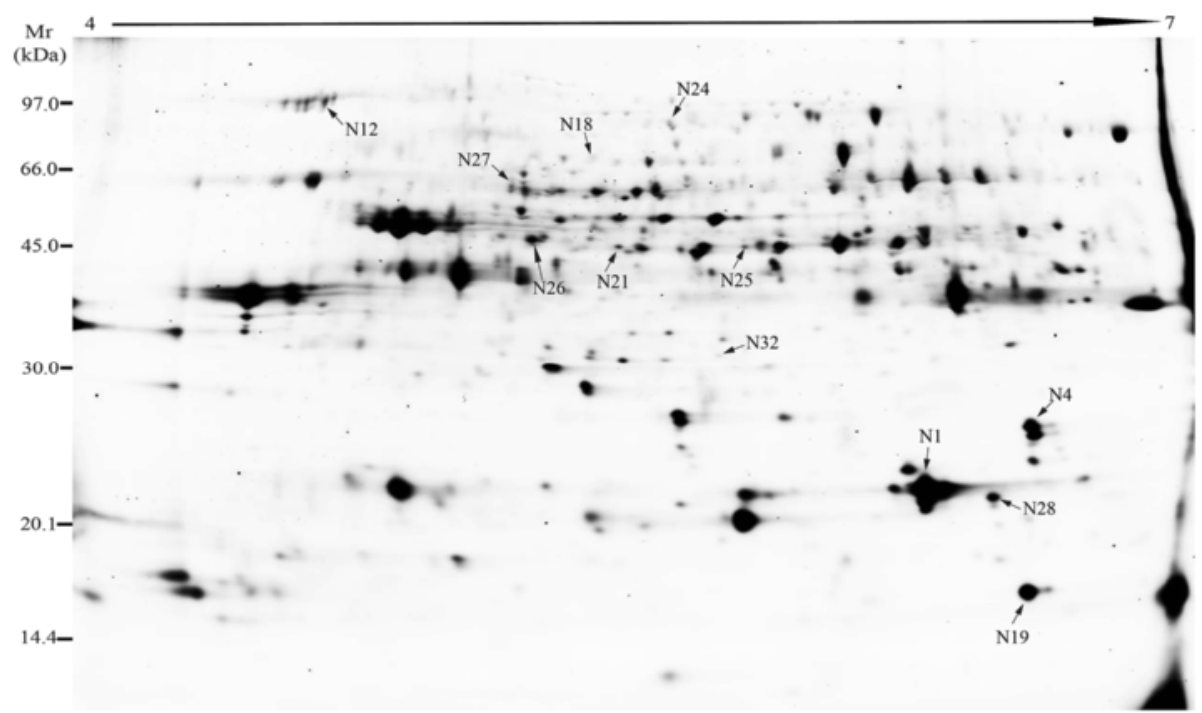

Fig. 1 2D-DIGE analysis of secreted proteins from Nipponbare suspension-cultured cells $0 \mathrm{~h}$ and $24 \mathrm{~h}$ after inoculation with Xoo. Secreted protein $(150 \mu \mathrm{g})$ from each sample were labeled with Cy3 and Cy5 respectively, loaded and separated on $24 \mathrm{~cm}$ strips $(\mathrm{pH}=4-7)$ in the first dimension, followed by electrophoresis on $12.5 \%$ SDS-PAGE gels in the second dimension. Gels were scanned with a DIGE scanner, merged and shown as a grayscale image. Protein spots responsive to Xoo-inoculation are marked by numbered arrows and identified in Tables 1 and 2. Relative mobility (Mr) markers were the protein ladder kit purchased from GE Healthcare (USA) 
Table 1 The list of Xoo-responsive secreted rice proteins in rice suspension-culture medium identified by MS/MS. The average fold change of Xoo-inoculated to mock (positive numbers) or mock to Xoo-inoculated (negative numbers) was calculated from three biological replicates

\begin{tabular}{|c|c|c|c|c|c|c|c|c|}
\hline $\mathrm{No}^{\mathrm{a}}$ & Accession No. & Locus & $\begin{array}{l}\text { Match } \\
\text { peptide }^{b}\end{array}$ & SC $\%^{\mathrm{C}}$ & $\begin{array}{l}\text { Average fold } \\
\text { change }^{d}\end{array}$ & Molecular function and or property & Cell location & SignalPe \\
\hline N18 & gi|115464537 & Os05g0482700 & 12 & 31 & $9.85 \pm 0.047$ & $\begin{array}{l}\text { 2,3-bisphosphoglycerate-independent } \\
\text { phosphoglycerate mutase }\end{array}$ & extracellular & - \\
\hline N19 & gi|125560875 & Osl_28556 & 5 & 34 & $8.19 \pm 0.016$ & $\begin{array}{l}\text { plastocyanin-like domain containing } \\
\text { protein, putative, expressed }\end{array}$ & extracellular & Yes \\
\hline N21 & gi|125560875 & Osl_28556 & 5 & 21 & $7.36 \pm 0.024$ & $\begin{array}{l}\text { plastocyanin-like domain containing } \\
\text { protein, putative, expressed }\end{array}$ & extracellular & Yes \\
\hline N24 & gi|222618730 & Os」_02342 & 13 & 15 & $5.2 \pm 0.024$ & beta-galactosidase & extracellular & Yes \\
\hline N26 & gi|115447367 & Os02g0621700 & 25 & 66 & $4.53 \pm 0.045$ & $\begin{array}{l}\text { succinyl-CoA ligase beta-chain, } \\
\text { mitochondrial precursor, putative, } \\
\text { expressed }\end{array}$ & mitochondrial & - \\
\hline N28 & gi|115473931 & Os07g0665200 & 8 & 64 & $1.63 \pm 0.043$ & $\begin{array}{l}\text { copper/zinc superoxide dismutase, } \\
\text { putative, expressed }\end{array}$ & cytoplasmic & - \\
\hline N27 & gi|115481730 & Os10g0370500 & 16 & 38 & $2.65 \pm 0.024$ & cellulase, putative, expressed & plasma membrane & Yes \\
\hline N32 & gi|115450541 & Os03g0132900 & 13 & 53 & $-5.83 \pm 0.024$ & $\begin{array}{l}\text { CHIT16 - family protein precursor, } \\
\text { expressed }\end{array}$ & extracellular & Yes \\
\hline
\end{tabular}

${ }^{a}$ spot number as given in Fig. 1. Some proteins from different spots correspond to the same gene suggesting they may have been post-translationally modified ${ }^{b}$ number of matched peptides

'sequence coverage

dFold change with $p<0.05$

SignalPe "Yes" means protein was predicted to have a signal peptide

beta-galactosidase, cellulase and CHIT16 contain signal sequences or cleavage sites. PRORT II prediction gave similar results to SignalP. Apart from succinyl-CoA ligase beta-chain and copper/zinc superoxide dismutase, the proteins were predicted to be extracellular or located in the plasma membrane (Table 1). These results help to confirm that our secreted-protein extraction method is suitable for 2D-DIGE analysis.

Nineteen differentially expressed protein spots corresponding to four unique proteins from Xoo (Fig. 2) were identified by BLAST in the Prosite, Pfam and InterPro databases and their predicted functions or properties are shown in Table 2. One is involved in degrading the rice cell wall (LipA, spot N25) and one in transport (transporter, spot N12), but the functions of the others are unclear. All are predicted to be located in the extracellular space by PSORT, and only one (Xoo3479, spot N1) has no signal peptide when analyzed in SignalP 4.1. Xoo3479 was not predicted to have a signal peptide when assessed with SecretomeP, and it is therefore possible that this protein was transported to the extracellular space through a nonclassical pathway.

To investigate the relationship between the identified proteins and their transcription, real time RT-PCR was performed to analyze the transcriptional activities of four randomly selected rice genes corresponding to the rice proteins identified. Samples were tested at $0 \mathrm{~h}, 24 \mathrm{~h}$, $48 \mathrm{~h}$, and $72 \mathrm{~h}$ after Xoo- inoculation. There was a poor correlation between changes in mRNAs and the corresponding proteins (Fig. 3). For example, 2,3-bisphosphoglycerate-independent phosphoglycerate mutase (Spot N18) and succinyl-CoA ligase (Spot N26) were up-regulated,

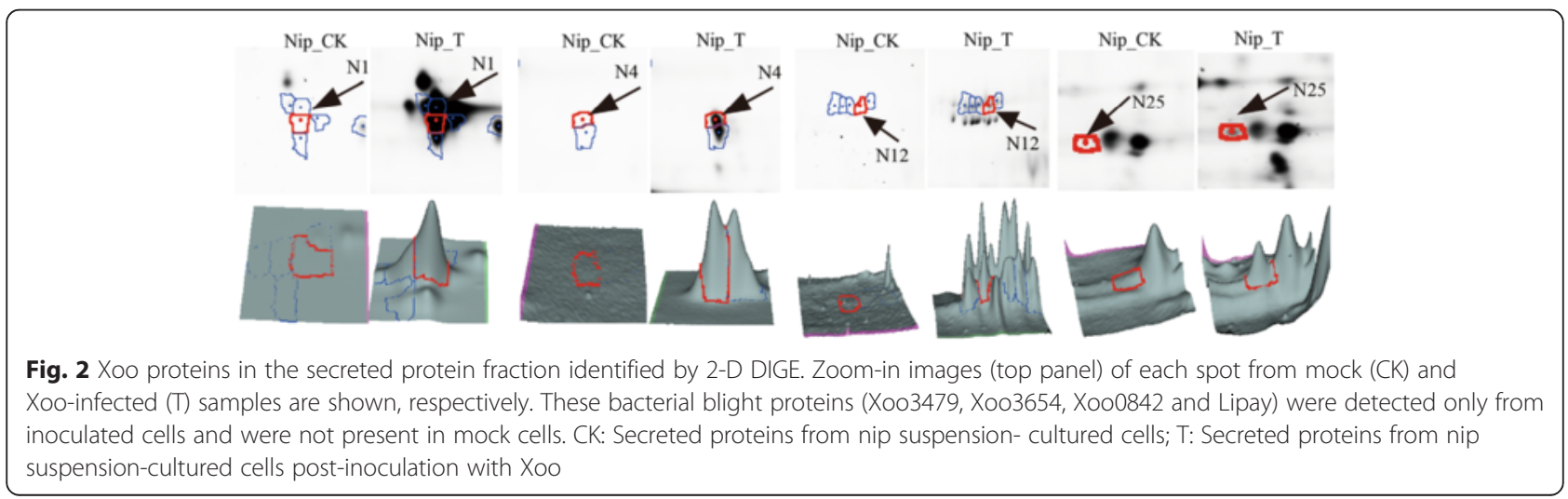


Table 2 The list of secreted Xoo proteins in rice suspension-culture medium identified by MS/MS

\begin{tabular}{|c|c|c|c|c|c|c|c|c|}
\hline $\mathrm{No}^{\mathrm{a}}$ & Accession No. & Protein name & Match peptide ${ }^{b}$ & SC $\%^{\mathrm{C}}$ & Average fold change $^{d}$ & Molecular function & Cell location & SignalP \\
\hline N1 & gi|58583102 & Hypothetical protein Xoo3479 & 12 & 95 & $157 \pm 0.013$ & Unclear & extracellular & - \\
\hline N4 & gi|84625311 & hypothetical protein Xoo3654 & 18 & 68 & $56.99 \pm 0.027$ & Unclear & extracellular & Yes \\
\hline $\mathrm{N} 12$ & gi|58580465 & hypothetical protein Xoo0842 & 20 & 30 & $14.23 \pm 0.023$ & Pathogenicity & extracellular & - \\
\hline N25 & gi|256032659 & Lipay & 10 & 46 & $4.92 \pm 0.024$ & Pathogenicity & extracellular & - \\
\hline
\end{tabular}

${ }^{\mathrm{a}}$ spot number as given in Fig. 1

${ }^{b}$ number of matched peptides

csequence coverage

${ }^{\mathrm{d}}$ Fold change with $p<0.05$

whereas their transcripts were down-regulated at $24 \mathrm{~h}$ and up-regulated at $48 \mathrm{~h}$. The transcript of the up-regulated copper/zinc superoxide dismutase was also downregulated at $24 \mathrm{~h}$. The mRNA transcriptional level does not always correlate well with the protein expression levels [28]. For example, the cold-stress response protein, 2,3- bisphosphoglycerate-independent phosphohlycerphate mutase, was up-regulated, but transcription was downregulated [29] similar to our results. The transcription of many PR proteins was first up and then down when treated with Jasmonate (JA) [30]. It should be noted that seedling leaves were used to measure transcript levels,

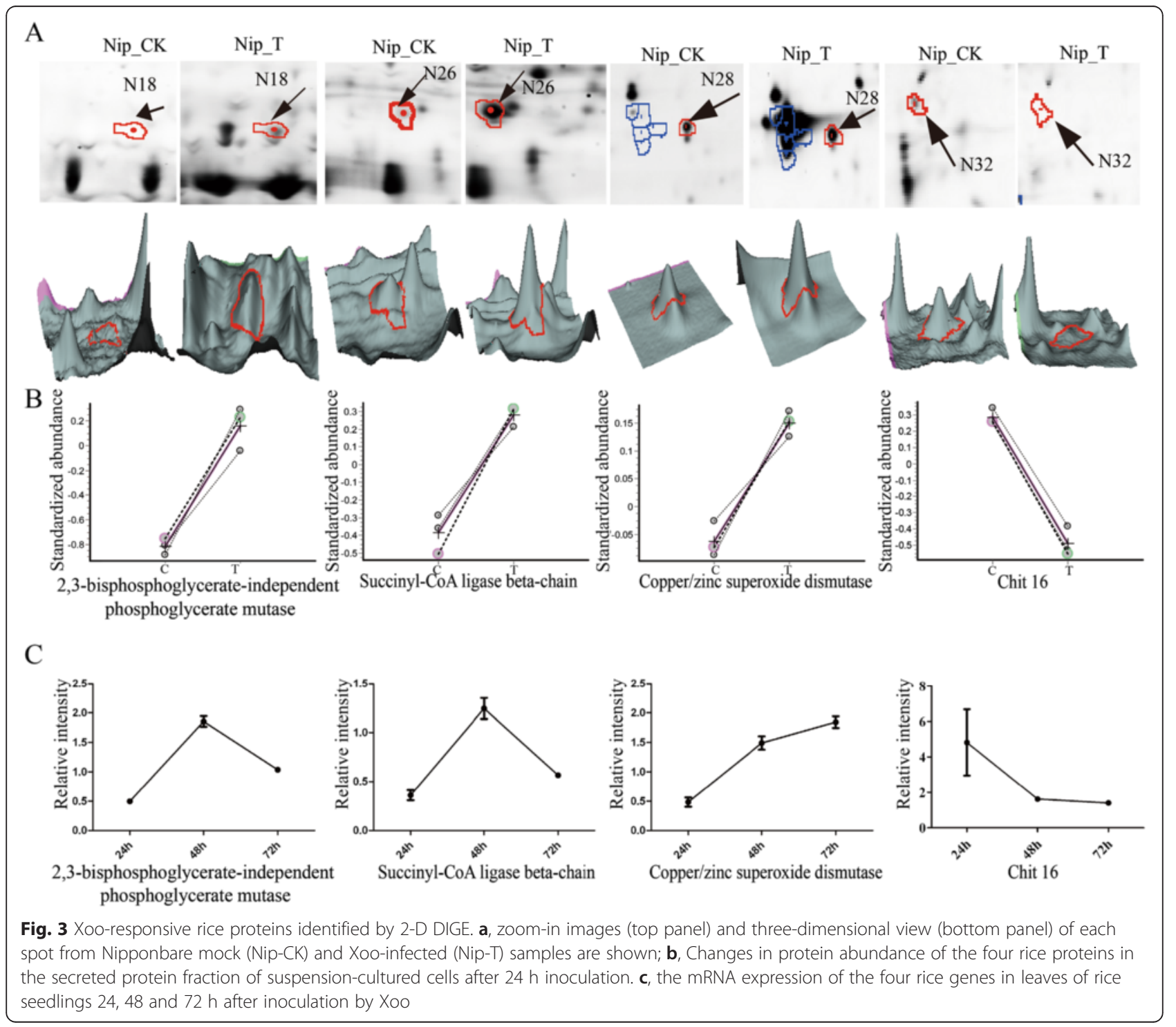


while the secreted protein levels were determined from suspension cultured cells. And gene expression in infected leaves may also influenced by the circadian rhythm.

The $\mathrm{N}$-and $\mathrm{C}$-termini of three candidate Xoo genes were fused with enhanced green fluorescent protein (GFP) and the 35S::GFP plasmids were transfected into rice protoplasst, repectively. The GFP fluorescent signals of Xoo0842, Xoo3479 and Xoo3654 were detected only in the plasma membrane of rice protoplasts, confirming their extracellular location (Fig. 4). This suggests that those Xoo proteins can be secreted into the extracellular space after expression in rice protoplasts, but further studies are needed to determine whether they are effectors or elicitors in pathogenicity.

To characterize the function of Xoo-3654 (X2) gene in pathogenicity, we cloned it into Xoo strain PXO124 (pHMX2-PXO124 ). Growth curve analysis showed that $\mathrm{X} 2$ slightly reduced the growth rate (Fig. 5a). qRT-PCR showed that the expression level of X2 in pHMX2PXO124 was over fifteen times higher than in pHM1PXO124 (Fig. 5b). In a virulence assay using the leaf clipping method (Fig. 5c \& d), pHMX2- PXO124 was less virulent than pHM1-PXO124, with shorter lesion length on leaves of adult rice (wild type). These results

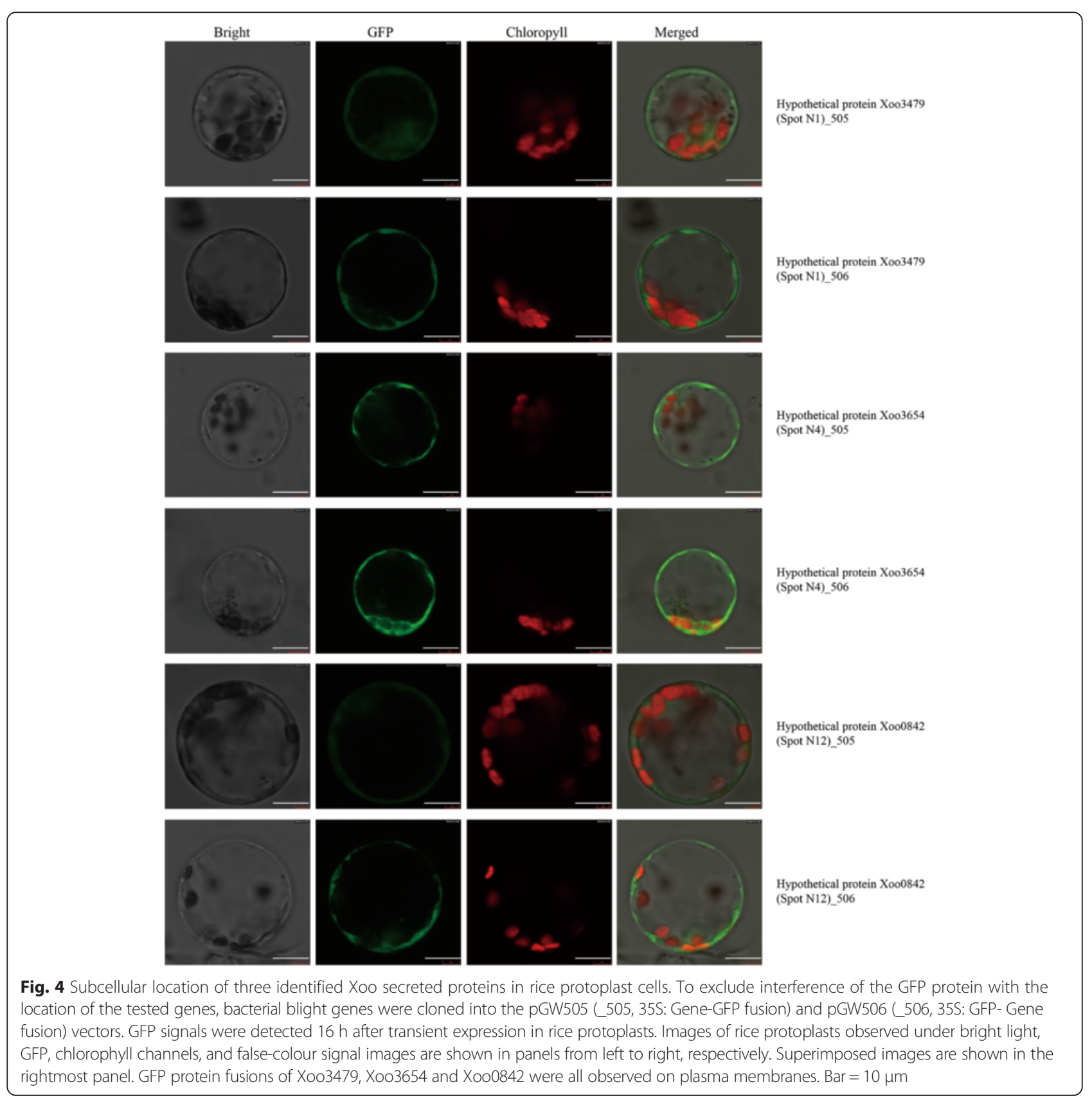



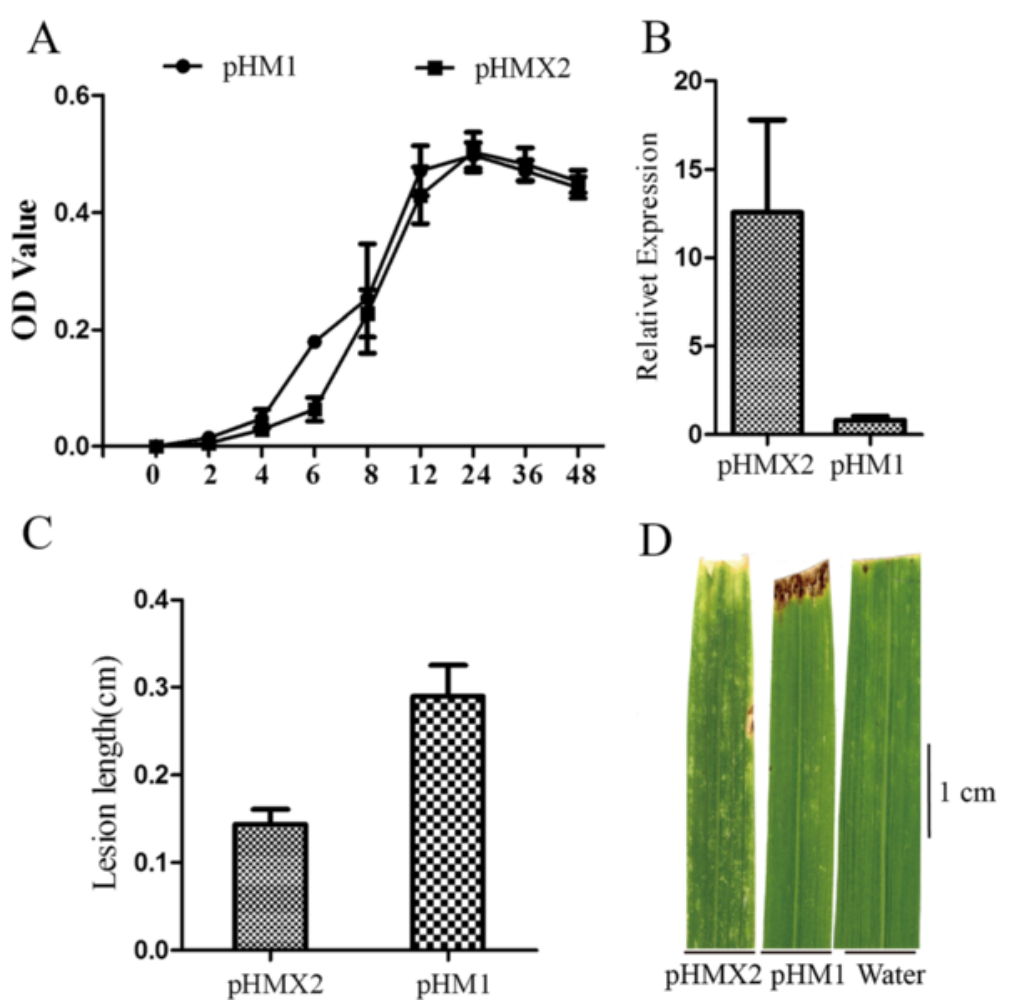

Fig. 5 Over-expression of Xoo_3654 (X2) in PXO124 and its effects on pathogenicity. a: Growth curve of construct strains pHMX2- PXO124 and pHM1-PXO124. Compared with mock plasmid pHM1, X2 slightly reduced the growth rate. $\mathbf{b}$ : Expression of X2 gene in construct strains pHMX2- PXO124 and pHM1-PXO124. Total RNA was extracted from pHM1-PXO124 and pHMX2-PXO124, and 500 ng RNA was reverse transcribed by the iscript CDNA synthesis kit (Bio-RAD) and quantified using qRT-PCR. 16 s-rDNA was used to normalize total RNA amounts. Expression levels of X2 in pHMX2-PXO124 are more than fifteen times higher than in PHM1-PXO124. c: Pathogenicity test showing reduction of lesion length in young leaves inoculated with pHMX2- PXO124 compared to those inoculated with pHM1-PXO124. d: Phenotypes of lesions in 21-dyas rice leaves inoculated with PHMX2-PXO124 and pHM1-PXO124 for 14 days

suggest that Xoo3654 acts as a negative regulator of this pathovar of Xoo.

\section{Discussion}

Secreted proteins play crucial roles in a number of physiological and pathological processes, such as growth and development [31], cell division and differentiation [32], defense- and stress-related responses [33]. Suspensionculture has been a preferred and widely used system for secretome analysis in plants and other organisms, including mammals [34], bacteria [25, 35] and fungi [36]. In this study, we used 2D-DIGE to analyze the secreted proteins in a rice embryo cell suspension culture challenged by Xoo.

Plants have evolved defense mechanisms to protect themselves from biotic and abiotic stresses, one of the most important of which involves Pathogenesis-Related proteins (PR proteins). Many chitinases are PRs, and can be induced by fungi [37], bacteria and viruses [38]. Chitinases are not only involved in plant growth and development [39], but also enhance plant defense [40].
Overexpression of chitinase can enhance defense against fungi in transgenic plants [41]. In this study, CHIT16 (Spot N32) is a chitinase belonging to the third group of the chitinase family. It contains a signal peptide and a transmembrane domain, which suggests that it is a secreted protein. However, this protein was down-regulated in response to Xoo infection. Plant susceptibility to pathogens is very complex, and may include non-recognition of the pathogen or inability to activate the defense system. Whether the down regulation of CHIT16 is the main cause of susceptibility of Nipponbare to Xoo needs to be further investigated. The structure of the cell wall can be modified in response to developmental or environmental stress [42]. Cellulose is the main structural component of the primary cell wall and is therefore one of the most important compounds in the first line of physical defense in green plants. Cellulases are enzymes that degrade cellulose into glucose. Although they are involved in cell growth and proliferation, they also have a destructive effect on cells [43]. Pathogen cellulases may also be associated with their pathogenicity [44]. Here, we observed one cellulase (Spot 
N27, Uniprot ID Q8RU06 ) that was up- regulated under the stress of Xoo infection. This cellulase may be involved in degrading the rice cells walls. It needs to be confirmed whether this response made the cells conducive to Xoo infection and so contributed to reduced host resistance.

Several proteins secreted from Xoo were identified in the culture medium, contrasting with results from a suspension culture of resistant rice cells (unpublished data). Although the pathogenicity of Xoo is quite complex, it is also genetically determined and observes the rules of "Special and Niche Characteristics" [45]. Aparna [46] found that Lipay (Spot N25) was an esterase, which is not only involved in degrading the rice cell wall, but also plays a role as a secretory virulence factor eliciting the innate immune response. There are no published studies on the other secreted proteins we identified (Xoo0842, Xoo3479 and Xoo3654). Bioinformatics analysis of Xoo0842 (Spots N12) in the NCBI database, suggests that it has six Lbr-YadA domains, one ESPR domain and two Hia domains. This suggests that Xoo0842 meybe can transported to the extracellular space through the type $\mathrm{V}$ secretory pathway, and may be a transport protein having the similar function of virulence to that of YadA. In the recent study of Wang et al. [25], Xoo0842 was only observed in infected leaves and not in vitro culture medium. We deduce that this protein is only expressed in infection of rice and may have some function of pathogenicty of PXO124. This still needs further validation. In Wang's study, Xoo3479 was detected in both the in vitro medium and, at higher levels, in infected leaves [25]. We also observed Xoo3479 (Spots N1) in Nipponbare suspension-cultured medium. Xoo3654 (Spot N4) is a novel secreted protein. Overexpression of Xoo3654 slightly reduced the pathogenicity of PXO124, suggesting its role as a negative regulator in bacterial virulence, although the detailed molecular mechanisms needs further investigation.

\section{Conclusions}

The rice - Xoo interaction is a classical model for studying plant - pathogen interactions. Here, we first use 2D-DIGE to analyze differentially expressed secreted proteins in susceptible rice suspension-cultured cells incubated with Xoo. The identified proteins are involved in various biological processes, including defense, cell wall modification, redox, glycolysis and the TCA cycle. In addition, four Xoo secreted proteins were also observed in this study. Subcellular location showed that three of these proteins were located in the extracellular region. Meanwhile, Xoo3654(X2) was shown to affect Xoo virulence as its overexpression leads to decreased pathogenicity. These results not only help us better understand the interaction between susceptible rice and Xoo, but also serve as a reference for studying the interaction between other plants and pathogens.

\section{Methods}

\section{Plant and bacterial material}

Mature rice seeds (O. sativa subsp. japonica var. Nipponbare) were dehulled and sterilized in $70 \%$ ethanol for 2 min and then in $20 \%$ sodium hypochlorite for another $30 \mathrm{~min}$ followed by extensive washing in distilled water to remove the disinfectant. Sterilized seeds were placed on $\mathrm{N} 6$ callus induction medium [47] at $28{ }^{\circ} \mathrm{C}$ under a $16 / 8 \mathrm{~h}$ light/dark photoperiod regime for one month to induce calli. Growing calli $(0.5-1.0 \mathrm{~g})$ were transferred into liquid N6 medium and shaken at $150 \mathrm{rpm}$ in the dark. The suspension culture was sub-cultured weekly until the cells appeared dense, uniform and light yellow. Xoo strain P10(PXO124) was cultured on PSA liquid medium (1\% w/ v peptone, $1 \% \mathrm{w} / \mathrm{v}$ sucrose) at $28{ }^{\circ} \mathrm{C}$ for $48 \mathrm{~h}$ and adjusted to $10^{8} \mathrm{CFU} \mathrm{ml}{ }^{-1}$ before inoculation to the rice suspension culture 3 days after sub-culturing. For pathogenicity assay, leaves from 21-d rice seedlings were inoculated with $\mathrm{Xoo}(\mathrm{OD}=\sim 0.8)$ using leaf-cutting method [48].

\section{Preparation of secreted proteins from rice suspension-cultured cells}

After sub-culturing for three days, the rice culture medium was harvested $0 \mathrm{~h}$ and $24 \mathrm{~h}$ after Xoo inoculation. Calli were removed by a nylon filter $(0.18 \mathrm{~mm})$. The filtered medium was centrifuged at $20000 \times \mathrm{g}$ for $20 \mathrm{~min}$ and the clear supernatant was freeze-dried. Total protein was extracted using a modified phenol-methanol method [26, 27]. At least three biological replicates were prepared. The secreted proteins were further purified using the 2-D Clean Up Kit (GE healthcare, USA) and their concentrations determined using a 2-D Quant kit (GE healthcare, USA).

\section{D-DIGE, image scanning and analysis}

Prepared secreted proteins were separated by 2D-DIGE as described previously [49]. The Cy2, Cy3, Cy5 labeled samples $(50 \mu \mathrm{g})$ were mixed and loaded on the strips (linear, $24 \mathrm{~cm}$, pI 4-7, GE Healthcare, USA) for the first dimension separation. Next, the strips were placed on top of $12.5 \%$ SDS-PAGE gels for the second dimension electrophoresis. Protein spots on gels were scanned using an Ettan DIGE Scanner (GE Healthcare, USA) and the images were analyzed using Decyder 2D software (Version 7.0, GE Healthcare, USA). Finally, spots from different gels were matched using Biological Variation Analysis. Only spots present in all gels and which exhibited statistically significant changes in intensity $(\geq 1.5$ fold or $\leq-1.5$ fold, $p<0.05$ ) were considered to be differentially expressed proteins.

\section{In gel digestion and MS analysis}

About $500 \mu \mathrm{g}$ secreted proteins were loaded on the strips, separated by $2-\mathrm{DE}$ and stained with Coomasie 
Brilliant Blue (CBB) R-250. Differentially expressed protein spots were manually excised from the stained 2-D gel and transferred to a sterile tube $(1.5 \mathrm{ml})$ with $30 \%$ (w/v) Acetonitrile (ACN) and $\mathrm{NH}_{4} \mathrm{HCO}_{3}(100 \mathrm{mmol})$ solution to remove the $\mathrm{CBB}$ stain. After vacuum drying, the spots were digested in $30 \mu \mathrm{l}$ enzyme buffer $(50 \mathrm{mmol}$ $\mathrm{NH}_{4} \mathrm{HCO}_{3}, 50 \mathrm{ng} / \mu \mathrm{l}$ trypsin (Sigma, USA)) at $37{ }^{\circ} \mathrm{C}$ overnight. Then, the small peptides were back extracted using $60 \%$ (w/v) ACN (containing $0.5 \%$ w/v trifluoroacetic acid (TFA)) and dried under a steam of nitrogen. Finally, the peptide samples were re-suspended in $0.8 \mu \mathrm{l}$ of $50 \%(\mathrm{w} / \mathrm{v}) \mathrm{ACN}$ (containing $0.1 \% \mathrm{w} / \mathrm{v}$ TFA and $5 \mathrm{mg} / \mathrm{ml}$ acyano-4-hydroxycinnamic acid(CHCA)) and analyzed using a ABI4700 MALDI-TOF/TOF mass spectrometer (Applied Biosystems, USA). All MALDI-TOF spectra were searched against the National Center for Biotechnology Information non-redundant (NCBInr) database using the GPS Explorer ${ }^{\mathrm{Tm}}$ software (v3.6, Applied Biosystems) and MASCOT search program (v2.1 Matrix Science). Finally, based on the MALDI-TOF-MS, only protein scores $>95(p<0.05)$ were accepted for the identification of protein samples.

\section{Bioinformatics analysis}

Homologues of the identified proteins were searched in the RAP-DB (http://rapdb.dna.affrc.go.jp/) and RAGP (http://rice.plantbiology.msu.edu/) databases for matching against the NCBI database. Then, UniProt (http://www. uniprot.org/) and Pfam (http://www.sanger.ac.uk/) databases were used to determine their functions. In addition, SignalP (version 4.1, http://www.cbs.dtu.dk/services/SignalP/) and SecretomeP (version 2.0, http://www.cbs.dtu. $\mathrm{dk} /$ services/SecretomeP/) were used to predict their secretion pathways and PSORT II (http://psort.hgc.jp/form2. html) to predict their subcellular location.

\section{RNA extraction and quantitative real time PCR for gene expression}

Primers were designed according to the gene sequences in the RAP-DB and RAGP databases, using Primer Premier 5.0 (Additional file 1: Table S1). Nipponbare seedlings were cultivated on greenhouse until the four to five-leave stage. The rice leaves were inoculated with Xoo at $0 \mathrm{~h}, 24 \mathrm{~h}, 48 \mathrm{~h}$ and72h post infection by leaf-cutting method [48]. Total RNA was extracted from infected rice leaves using TRIzol reagent (Invitrogen, Germany). Residual DNA was removed by DNase I RNase free (TaKaRa, Japan) and the first strand cDNA was synthesized using the Synthesis Kit for RT-qPCR (Bio-RAD, USA) following the manufacturer's instructions. Real time PCR with SYBR Green Real time PCR Master Mix (TOYOBO, Japan) was performed on a 7900HT Fast Real time PCER system (Life Technologies, USA), and PCR conditions were as follows: $94{ }^{\circ} \mathrm{C}$ for $3 \mathrm{~min}$, then 45 cycles of $95{ }^{\circ} \mathrm{C}$ for $30 \mathrm{~s}, 58^{\circ} \mathrm{C}$ for
$45 \mathrm{~s}$ and $72{ }^{\circ} \mathrm{C}$ for 45 s. Actin (AK060893) was used as a reference gene, and the relative gene expression was calculated using the $2^{-\Delta \Delta c t}$ method. All experiments were performed in triplicate with the cDNA prepared from different samples.

\section{Vector construction and subcellular localization of Xoo identified proteins}

The cDNAs of Xoo0842, Xoo3479 and Xoo3654 were amplified using their respective primers (Additional file 1: Table S2), and the full-length coding regions were fused in-frame with GFP in pGW505 and pGW506 using the Gateway technology (Invitrogen, USA) followed by transient expression in rice protoplast cells, using the rice protoplast gene expression system and the PEG method [49]. The GFP signal was excited at $395 \mathrm{~nm}$ and observed at 450-490 nm using a confocal laser scanning microscope (Olympus, Japan). Chlorophyll signals were excited at $436 \mathrm{~nm}$ and observed at 500-530 nm.

\section{Over-expression of Xoo3654 in PX0124 and growth assay analysis}

To investigate whether Xoo3654 affects pathogenicity, we cloned its coding region and inserted it into pHM1, a expressing vector with the constitutive lac promoter [50]. The resultant vector pHMXoo3654 (pHMX2) was verified by sequencing (Biosune, Hangzhou, China). Purified pHMX2 and pHM1 (mock) plasmids were electroporated into PXO124(P10) competent cells. The transformed cells were selected on NA medium ( $1 \%$ tryptone, $0.1 \%$ yeast extract, $1 \%$ sucrose, $0.3 \%$ peptone, $1.5 \%$ agar) containing $\operatorname{spectinomycin}\left(25 \mu \mathrm{g} \cdot \mathrm{mL}^{-1}\right)$ at $28{ }^{\circ} \mathrm{C}$ for $4 \mathrm{~d}$, and were subsequently verified by sequencing (Biosune, Hangzhou, China). For the growth assay, the colonies of Xoo strains were grown in NB medium (NA medium without agar) for $24 \mathrm{~h}$. Then, $100 \mu \mathrm{l}$ of culture medium of each strain adjusted to $0.5 \times 10^{8}$ colony formation units (CFU) per ml, was inoculated into fresh NA liquid medium and shaken at $200 \mathrm{rpm}$ at $28{ }^{\circ} \mathrm{C}$. Three replicate samples were collected at each indicated time point (up to $48 \mathrm{~h}$ ), and their optical densities were measured at $600 \mathrm{~nm}\left(\mathrm{OD}_{600}\right)$.

\section{RT-PCR for X2 construct and its effect on pathogenicity}

Total RNA extraction from construct strains and quantitative real time PCR for Xoo3654 were performed using the methods described above for Nipponbare. The $16 \mathrm{~s}$ rDNA was used to normalize total RNA amount. For pathogenicity tests, constructs Xoo $\left(\mathrm{OD}_{600}=0.8\right)$ were incubated into 45-day rice using the leaf-cutting method, and NA medium was used as a control. The infected plants were grown in a green house at $25-30{ }^{\circ} \mathrm{C}$ with a $12 \mathrm{~h}$ photoperiod and $60 \%$ relative humidity. The lesion length was measured 14 days later. Each experiment was conducted three times. 


\section{Additional files}

Additional file 1: Table S1. Primer sequences used for quantitative RTPCR of differentially expressed genes in susceptible rice subject to Xoo inoculation. (DOCX $14.3 \mathrm{~kb}$ )

Additional file 2: Table S2. Primer sequences used for transient expression of Xoo genes in rice protoplast cells. (DOCX $13.8 \mathrm{~kb}$ )

Additional file 3: Table S3. Primer sequences used for over-expression and RT-PCR of Xoo3654 gene. (DOCX $14.1 \mathrm{~kb}$ )

\section{Abbreviations}

2-D DIGE: two-dimensional difference in gel electrophoresis; ACN: Acetonitrile; BB: bacterial blight; CHCA: a- cyano -4-hydroxycinnamic acid; CHIT 16: chitinase 16; MS: mass spectrometry; NB-LRR: nucleotidebinding site leucine-rich repeat; TCA: tricarboxylic acid cycle; TFA: trifluoroacetic acid.

\section{Competing interests}

The authors declare that they have no competing interests.

\section{Authors' contributions}

$X C$ carried out the experiments, analyzed the data and drafted the manuscript. CY and ZD analyzed the data and helped to draft the manuscript. CY and JC conceived of the study, designed the experiments and revised the manuscript. All authors read and approved the final manuscript.

\section{Acknowledgements}

This research was supported by grants from the Hi-Tech Program ('863' Program) of China, Ministry of Science and Technology (Grant 2014A0A603-15) and State Basic Research Programof China (2014CB160309, 2014CB138403), the Zhejiang Provincial Foundation for Natural Science (Grant 2014C140001, Y3090665), and Key Subject Construction Program of Zhejiang for Modern Agricultural Biotechnology and Crop Disease Control. We thank Dr Xuming Wang (Zhejiang Academy of Agricultural Sciences,ZAAS) for providing vectors pGW505 and pGW506, Dr Yong Yang (ZAAS) for providing rice seeds 9311, Dr Jie Zhou (ZAAS) for providing advice on subcellular location on rice protoplast, Professor Chen GongYou (Shanghai Jiao Tong University, SJTU) for providing vector pHM1 and Professor M. J. Adams (Stevenage, UK) for his correction of the English manuscript.

\section{Author details}

${ }^{1}$ College of Agriculture and Biotechnology, Zhejiang University, Hangzhou, China. ${ }^{2}$ State Key Laboratory Breeding Base for Zhejiang Sustainable Pest and Disease Control, MOA Key Laboratory of Biotechnology in Plant Protection, Zhejiang Provincial Key Laboratory of Plant Virology, Institute of Virology and Biotechnology, Zhejiang Academy of Agricultural Science, Hangzhou 310021, China.

\section{Received: 2 September 2015 Accepted: 17 January 2016}

Published online: 02 February 2016

\section{References}

1. Swings J, Van Den Mooter M, Vauterin L, Hoste B, Gillis M, Mew TW, et al. Reclassification of the Causal Agents of Bacterial Blight (Xanthomonas campestris pv. oryzae) and Bacterial Leaf Streak (Xanthomonas campestris pv. oryzicola) of Rice as Pathovars of Xanthomonas oryzae (ex Ishiyama 1922) sp. nov., nom. rev. Int J Syst Evol Microbiol. 1990;40:309-11.

2. Zhu W, MaGbanua MM, White FF. Identification of two novel hrp-associated genes in the hrp gene cluster of Xanthomonas oryzae pv. oryzae. J Bacteriol. 2000;182:1844-53.

3. White FF, Yang B. Host and pathogen factors controlling the riceXanthomonas oryzae interaction. Plant Physiol. 2009;150:1677-86.

4. Verdier V, Vera Cruz C, Leach JE. Controlling rice bacterial blight in Africa: needs and prospects. J Biotechnol. 2012;159:320-8.

5. Das B, Sengupta S, Prasad M, Ghose TK. Genetic diversity of the conserved motifs of six bacterial leaf blight resistance genes in a set of rice landraces. BMC Genet. 2014;15:82
6. Liu W, Liu J, Triplett L, Leach JE, Wang GL. Novel insights into rice innate immunity against bacterial and fungal pathogens. Annu Rev Phytopathol. 2014;52:213-41.

7. Shanti ML, George M, Cruz CV, Bernardo M, Nelson R, Leung H, et al. Identification of resistance genes effective against rice bacterial blight pathogen in eastern India. Plant Dis. 2001;85:506-12.

8. Chu Z, Fu B, Yang H, Xu C, Li Z, Sanchez A, et al. Targeting xa13, a recessive gene for bacterial blight resistance in rice. Theor Appl Genet. 2006;112:455-61.

9. Song WY, Wang GL, Chen LL, Kim HS, Pi LY, Holsten T, et al. A receptor kinase-like protein encoded by the rice disease resistance gene, Xa21. Science. 1995;270:1804-6.

10. Zhou YL, Uzokwe VN, Zhang $\mathrm{CH}$, Cheng LR, Wang L, Chen $\mathrm{K}$, et al. Improvement of bacterial blight resistance of hybrid rice in China using the Xa23 gene derived from wild rice (Oryza rufipogon). Crop Prot. 2011;30:637-44.

11. Gu K, Yang B, Tian D, Wu L, Wang D, Sreekala C, et al. R gene expression induced by a type-III effector triggers disease resistance in rice. Nature. 2005:435:1122-5.

12. Kuhara S, Sekiya N, Tagami Y. On the pathogen of bacterial leaf blight of rice isolated from severely affected area where resistant variety was widely cultivated. Ann Phytopathol Soc Jpn. 1958;23(1):9.

13. Hulbert SH, Webb CA, Smith SM, Sun Q. Resistance gene complexes: evolution and utilization. Annu Rev Phytopathol. 2001;39:285-312.

14. Salinari S, Debard C, Bertuzzi A, Durand C, Zimmet $P$, Vidal H, et al. Jejunal proteins secreted by $\mathrm{db} / \mathrm{db}$ mice or insulin-resistant humans impair the insulin signaling and determine insulin resistance. PLoS One. 2013;8, e56258.

15. Cesari S, Thilliez G, Cc R, $\operatorname{Vr} C$, Michel C, Jauneau A, et al. The rice resistance protein pair RGA4/RGA5 recognizes the Magnaporthe oryzae effectors AVRPia and AVR1-CO39 by direct binding. Plant Cell. 2013;25:1463-81.

16. Agrawal GK, Jwa NS, Lebrun MH, Job D, Rakwal R. Plant secretome: unlocking secrets of the secreted proteins. Proteomics. 2010;10:799-827.

17. Hathout Y. Approaches to the study of the cell secretome. Expert Rev Proteomics. 2007:4:239-48.

18. Ndimba BK, Chivasa S, Hamilton JM, Simon WJ, Slabas AR. Proteomic analysis of changes in the extracellular matrix of Arabidopsis cell suspension cultures induced by fungal elicitors. Proteomics. 2003;3:1047-59.

19. Chivasa S, Simon WJ, Yu XL, Yalpani N, Slabas AR. Pathogen elicitor-induced changes in the maize extracellular matrix proteome. Proteomics. 2005;5: 4894-904

20. Okushima Y, Koizumi N, Kusano T, Sano H. Secreted proteins of tobacco cultured BY2 cells: identification of a new member of pathogenesis-related proteins. Plant Mol Biol. 2000;42:479-88.

21. Kusumawati L, Imin N, Djordjevic MA. Characterization of the secretome of suspension cultures of Medicago species reveals proteins important for defense and development. J Proteome Res. 2008;7:4508-20.

22. Kim ST, Kang YH, Wang Y, Wu J, Park ZY, Rakwal R, et al. Secretome analysis of differentially induced proteins in rice suspension-cultured cells triggered by rice blast fungus and elicitor. Proteomics. 2009;9:1302-13.

23. Kaffarnik FA, Jones AM, Rathjen JP, Peck SC. Effector proteins of the bacterial pathogen Pseudomonas syringae alter the extracellular proteome of the host plant, Arabidopsis thaliana. Mol Cell Proteomics. 2009;8:145-56.

24. Chen F, Yuan Y, Li Q, He Z. Proteomic analysis of rice plasma membrane reveals proteins involved in early defense response to bacterial blight. Proteomics. 2007:7:1529-39.

25. Wang Y, Kim SG, Wu J, Huh HH, Lee SJ, Rakwal R, et al. Secretome analysis of the rice bacterium Xanthomonas oryzae (Xoo) using in vitro and in planta systems. Proteomics. 2013;13:1901-12.

26. Deng Z, Zhang X, Tang W, Oses-Prieto JA, Suzuki N, Gendron JM, et al. A proteomics study of brassinosteroid response in Arabidopsis. Mol Cell Proteomics. 2007;6:2058-71.

27. Kim JY, Wu J, Kwon SJ, Oh H, Lee SE, Kim SG, et al. Proteomics of rice and Cochliobolus miyabeanus fungal interaction: Insight into proteins at intracellular and extracellular spaces. Proteomics. 2014:14:2307-18.

28. Yan SP, Zhang QY, Tang ZC, Su WA, Sun WN. Comparative proteomic analysis provides new insights into chilling stress responses in rice. Mol Cell Proteomics. 2006;5:484-96.

29. Gao F, Zhou Y, Zhu W, Li X, Fan L, Zhang G. Proteomic analysis of cold stress-responsive proteins in Thellungiella rosette leaves. Planta. 2009;230: 1033-46.

30. Ding CK, Wang CY, Gross KC, Smith DL. Jasmonate and salicylate induce the expression of pathogenesis-related-protein genes and increase resistance to chilling injury in tomato fruit. Planta. 2002;214:895-901. 
31. Mason ED, Konrad KD, Webb CD, Marsh JL. Dorsal midline fate in Drosophila embryos requires twisted gastrulation, a gene encoding a secreted protein related to human connective tissue growth factor. Genes Dev. 1994:8:1489-501.

32. Claffey KP, Wilkison W, Spiegelman B. Vascular endothelial growth factor. Regulation by cell differentiation and activated second messenger pathways. J Biol Chem. 1992;267:16317-22.

33. Seidl V, Marchetti M, Schandl R, Allmaier G, Kubicek CP. Epl1, the major secreted protein of Hypocrea atroviridis on glucose, is a member of a strongly conserved protein family comprising plant defense response elicitors. FEBS J. 2006;273:4346-59.

34. Robinson MW, Menon R, Donnelly SM, Dalton JP, Ranganathan S. An integrated transcriptomics and proteomics analysis of the secretome of the helminth pathogen Fasciola hepatica: proteins associated with invasion and infection of the mammalian host. Mol Cell Proteomics. 2009:8:1891-907.

35. Bumann D, Aksu S, Wendland M, Janek K, Zimny-Arndt U, Sabarth N, et al. Proteome analysis of secreted proteins of the gastric pathogen Helicobacter pylori. Infect Immun. 2002;70:3396-403.

36. Suárez MB, Sanz L, Chamorro MI, Rey M, González FJ, Llobell A, et al. Proteomic analysis of secreted proteins from Trichoderma harzianum: Identification of a fungal cell wall-induced aspartic protease. Fungal Genet Biol. 2005:42:924-34.

37. Bravo JM, Campo S, Murillo I, Ma C, San Segundo B. Fungus-and wound induced accumulation of mRNA containing a class II chitinase of the pathogenesis-related protein 4 (PR-4) family of maize. Plant Mol Biol. 2003; 52:745-59.

38. Métraux JP, Boller T. Local and systemic induction of chitinase in cucumber plants in response to viral, bacterial and fungal infections. Physiol Mol Plant Patho. 1986;28:161-9.

39. Schmidt ED, de Jong AJ, de Vries SC. Signal molecules involved in plant embryogenesis. Plant Mol Biol. 1994;26:1305-13.

40. Grover A. Plant chitinases: genetic diversity and physiological roles. Crit Rev Plant Sci. 2012;31:57-73.

41. Nishizawa Y, Nishio Z, Nakazono K, Soma M, Nakajima E, Ugaki M, et al. Enhanced resistance to blast (Magnaporthe grisea) in transgenic Japonica rice by constitutive expression of rice chitinase. Theor Appl Genet. 1999;99: 383-90.

42. Caño-Delgado A, Penfield S, Smith C, Catley M, Bevan M. Reduced cellulose synthesis invokes lignification and defense responses in Arabidopsis thaliana. Plant J. 2003;34:351-62.

43. Li M, Xiong G, Li R, Cui J, Tang D, Zhang B, et al. Rice cellulose synthase-like D4 is essential for normal cell-wall biosynthesis and plant growth. Plant J. 2009;60:1055-69.

44. Grenville-Briggs LJ, Anderson VL, Fugelstad J, Avrova AO, Bouzenzana J, Williams $A$, et al. Cellulose synthesis in Phytophthora infestans is required for normal appressorium formation and successful infection of potato. Plant Cell. 2008;20:720-38.

45. Chen GY, Zou LF, Wang XP, Xiang Y, Wang J. Molecular Genetics of Pathogenicity Determinants of Xanthomonas oryzae pv. oryzae. Scientia Agricultura Sinica. 2004;9:1301-7.

46. Aparna G, Chatterjee A, Sonti RV, Sankaranarayanan R. A cell wall-degrading esterase of Xanthomonas oryzae requires a unique substrate recognition module for pathogenesis on rice. Plant Cell. 2009;21:1860-73.

47. Fu FL, Li WC, Rong TZ. Effect of $\mathrm{Ca}(2+)$ and Uniconazole Appended in N6 Medium on Immature Embryos Culture in Maize. Acta Agronomica Sinica. 2005;31:634-9.

48. Kauffman H, Reddy A, Hsieh S, Merca S. Improved technique for evaluating resistance of rice varieties to Xanthomonas oryzae. Plant Dis Reptr. 1973;57: 537-41.

49. Zhang Y, Su J, Duan S, Ao Y, Dai J, Liu J, et al. A highly efficient rice green tissue protoplast system for transient gene expression and studying light/ chloroplast-related processes. Plant Methods. 2011;7:30.

50. Wang $L$, Zhang $L$, Geng $Y$, Xi W, Fang $R$, Jia $Y$. XerR, a negative regulator of $\mathrm{XccR}$ in Xanthomonas campestris pv. campestris, relieves its repressor function in planta. Cell Res. 2011;21:1131-42.

\section{Submit your next manuscript to BioMed Central and we will help you at every step:}

- We accept pre-submission inquiries

- Our selector tool helps you to find the most relevant journal

- We provide round the clock customer support

- Convenient online submission

- Thorough peer review

- Inclusion in PubMed and all major indexing services

- Maximum visibility for your research

Submit your manuscript at www.biomedcentral.com/submit
Biomed Central 